\title{
EDUCAÇÃO AMBIENTAL CRÍTICA: (RE)PENSAR A FORMAÇÃO INICIAL DE PROFESSORES/AS
}

\author{
Theóffillo da Silva Lopes ${ }^{1}$ \\ Francisco José Pegado Abílio²
}

Resumo: Este trabalho objetivou refletir sobre a Educação Ambiental crítica, repensando os pressupostos e as abordagens que são solícitas na formação inicial de professores/as, tendo como teleologia desse processo a própria emancipação humana. O diálogo construído baseia-se nos fundamentos ontológicos do ser social, nas categorias presentes nas discussões ambientais, na dialética e na complexidade da Educação Ambiental a partir do olhar da transdisciplinaridade, da ideologia e das práticas pedagógicas presentes na formação docente. Como conclusões, compreende-se que a Educação Ambiental crítica contribui para emancipação e transformação de ações e concepções dos indivíduos diante de si e do mundo.

Palavras-chave: Educação Ambiental Crítica; Emancipação; Formação Inicial de Professores/as.

Abstract: This work aimed to reflect on critical environmental education, rethinking the assumptions and approaches that are required in the initial training of teachers, having the human emancipation as the teleology of this process. The dialogue built is based on the ontological foundations of the social being, in the categories present in environmental discussions, in the dialectic and in the complexity of environmental education from the perspective of transdisciplinarity and in the ideology and pedagogical practices present in teacher training. As conclusions, it is understood that critical environmental education contributes to the emancipation and transformation of individuals' actions and conceptions before themselves and the world.

Keywords: Critical Environmental Education; Emancipation; Initial Teacher Training.

1 Universidade Federal da Paraíba. E-mail: theoffillo@outlook.com, Link para o lattes: http://lattes.cnpq.br/9345655247489359.

2 Universidade Federal da Paraíba. E-mail: chicopegado@yahoo.com.br, Link para o lattes: http://lattes.cnpq.br/3509554568530853. 


\section{Introdução}

Quando pensamos em uma Educação Ambiental enquanto prática social, que promova emancipação humana, pensamos em uma ação que rompa com modelos de ensino tecnicistas ou positivistas, os quais permeiam a transmissão de conhecimentos, a mudança de comportamento através de sensibilização e uma visão romantizada e naturalista.

Nesse contexto, a Educação Ambiental Crítica se apresenta como uma prática que auxilia e combate a crise ambiental, compreendida em seu caráter político, não somente como uma ação de conhecimento da natureza, dos recursos naturais e ecológicos, mas também emancipadora, cidadã, crítica e reflexiva, uma vez que compreende a complexidade da totalidade incluindo dimensões distintas, porém, unidas na crise pela qual passamos para contribuir com a transformação da realidade (LOUREIRO, 2011).

Loureiro (2019) reafirma esse pensamento quando expõe a ideia de que, uma vez que se reconhece e busca aplicar uma Educação Ambiental, com intencionalidade e dimensão complexa, de caráter interdisciplinar e transversal, é primaz pensar como ela se fará eficaz e fluida para dar conta de estudos que se perpassam em conhecimentos científicos, éticos, estéticos, tecnológicos, sociais, culturais e políticos.

Essa educação, imbricada à dimensão ambiental, amparada em um pensamento crítico, tem como desafio romper com o pensamento positivista de apropriação da natureza para desenvolvimento econômico; e com a racionalidade capitalista da modernidade, de absorção dos discursos ambientais para fins de crescimento econômico. A educação enquanto prática social de espaço de construção histórico-cultural, capaz de auxiliar nas transformações da realidade, necessita estar amparada em uma racionalidade ambiental, baseada na reflexão crítica, levando em consideração os problemas locais para atuação no global e a situação global interferindo nas estratégias locais. Leff (2008) apresenta essa racionalidade de uma forma que integre os processos ecológicos, tecnológicos e culturais para gerar um desenvolvimento alternativo, baseado em princípios de equidade, diversidade e democracia.

Nessa perspectiva, Reigota (2014) defende que as características de uma educação e ambiente carregados de interesses, convicções e conhecimentos científicos, políticos, filosóficos, religiosos e profissionais faz com que a Educação Ambiental esteja impregnada da utopia de mudar radicalmente as relações que conhecemos hoje, e de forma crítica, sejam essas relações entre a humanidade ou entre esta e a natureza.

Assim, a Educação Ambiental crítica se apresenta como um posicionamento ético e político dentro de um campo diverso de práticas, valores e visões de mundo. Busca não somente as mudanças comportamentais e individuais, mas transformações necessárias para enfrentar as crises ambientais e sociais vigentes, de modo que sejam alcançadas 
através das mudanças sociais e estruturais e da emancipação dos sujeitos envolvidos em suas práticas (LAYRARGUES, 2011).

Essa perspectiva de uma Educação Ambiental, por intermédio de um olhar crítico, parece estar ancorada no discurso de professores/as e na formação docente deles(as), porém, as práticas docentes parecem distantes. Em estudo realizado, Almeida (2013) observa que existe, ainda, uma visão naturalista da Educação Ambiental, com concepções que se resumem à preservação da natureza, ao lixo, às paisagens naturais, aos animais etc.

Diante disso, este trabalho objetivou refletir sobre a Educação Ambiental crítica, repensando os pressupostos e as abordagens que são solícitas na formação inicial de professores/as, tendo como teleologia desse processo a própria emancipação humana e o entendimento do inacabamento da conscientização dos indivíduos diante de si, do outro e do mundo.

\section{Por uma Educação Ambiental para a emancipação}

Pensar a Educação Ambiental como uma prática que ultrapassa 0 caráter instrumental de finalidade de mudança comportamental e adentra a concepção de emancipação humana, requer compreendê-la como uma prática social, baseada em uma ontologia que reconhece o ser humano como um ser social (LUKACS, 2018), uma vez que promove não somente a realização do movimento histórico no qual ele está inserido, como também o reconhecimento de que os problemas ambientais estão atrelados aos problemas sociais existentes.

Para isso, é primaz reconhecer a necessidade de uma base ontológica para a Educação Ambiental, a qual torne lúcida a compreensão de como os indivíduos entendem a construção do ser social e a relação deste com o restante da natureza.

Para Lukacs (2018), a peculiaridade da autocompreensão do ser humano é decisivamente determinada pelas atividades que perfazem a estrutura econômica e organizacional da sociedade; visto que promovem ou inibem, nos indivíduos, essa autocompreensão. Essas atividades estão ligadas às relações de poder de diversas instituições sociais, como as escolas, a cultura, a mídia, a religião ou o Estado.

Nesse aspecto de autocompreensão do ser humano, por muito tempo a ciência não pôde ou não se interessou em ir além do que já estava posto pela religião. Uma ontologia de dominação da natureza, em que o ser humano se sobrepõe a qualquer outro aspecto natural e o explora para usufruir dele. Sendo assim, a religião detinha a mais ampla margem para uma livre interpretação do mundo e do lugar do humano nele.

Com a chegada do positivismo, da modernidade e do pensamento cartesiano dentro do desenvolvimento da filosofia e da epistemologia, a ontologia foi aos poucos sendo substituída por uma gnosiologia de neutralidade 
das relações entre o sujeito e o objeto e em todas as questões relativas à concepção de mundo. O que Lukacs (2018) apresenta como uma suspensão de tudo aquilo que é ontológico e da remoção dos problemas referentes àquilo que é em si. Dessa feita, a prática educativa e a científica perdem a essência de pensar a relação do ser com o mundo e com sua espécie. Em uma corrente darwinista, transforma essas relações na sobrevivência do mais forte.

Nesse sentido, faz-se necessário trazer as discussões da Educação Ambiental para a ontologia do ser que se estuda e para o qual se almejam transformações. Um ser que busca a criação de uma consciência que seja capaz de conviver com o restante da natureza de forma equilibrada. Todavia, para isso, é primaz a compreensão do que Marx (1985) já ponderava em sua crítica da economia política, de que não é a consciência dos homens que determina o seu ser, e nesse caso produz transformações, mas é o seu ser social que inversamente determina sua consciência.

A compreensão de que a produção e a reprodução das condições de existência pela mediação do trabalho e do modo humano de apropriação da natureza institui, como afirma Chauí (2012), em cada época, o sistema de formas produtivas e consumistas que regulam a sociedade e traz para a Educação Ambiental a discussão de como os seres humanos produzem sua própria existência material e as ideias que simbolizam sua existência e sua relação com o restante da natureza.

Essa compreensão do ser humano como um ser social, que constrói sua consciência a partir das determinações sociais que o envolvem, de sua relação com o trabalho, com os meios de produção e de consumo e com as forças produtivas, não significa a separação da sociedade da natureza. A Educação Ambiental, enquanto prática educativa crítica, busca o entendimento da dialética presente na ontologia do ser social, que não deixa de ser natural. Como aponta Lucaks (2018), impera a consideração de que os problemas da natureza, predominantemente, estiveram atrelados à inter-relação desta com a sociedade.

Dessa forma, incorporar a ontologia do ser social à Educação Ambiental, requer a rejeição de qualquer transposição simplista das leis naturais para a sociedade e a independência do ser da natureza, como se fosse uma antítese. É necessária a compreensão da unidade do ser social, porque, como aponta Lucaks (2018, p. 286), "o ser social pressupõe, em seu conjunto e em cada um dos seus processos singulares, o ser da natureza inorgânica e da natureza orgânica".

Para a compreensão dessa ontologia de um ser social, que se posiciona através da sua autocompreensão diante do mundo e das atitudes para com este, faz-se necessário também a inserção de categorias nas discussões da Educação Ambiental, a fim de que se ofereça suporte às reflexões sobre como as crises ambientais estão vinculadas às crises sociais existentes; a saber: 0 trabalho, a totalidade e a práxis. 
Enquanto categoria que se desenvolve na ação humana sobre a natureza, o trabalho representa a base material da crise ambiental, uma vez que nele estão a produção e a acumulação de riquezas; as relações dos modos de produção e de consumo; de exploração e espoliação da natureza e até dos próprios seres humanos. Como aponta Layrargues (2011):

É a consideração da categoria trabalho que fornece a concretude necessária para que seja possível visualizar que os humanos não são seres vivos genéricos e abstratos para serem qualificados linearmente numa relação humanonatureza, como é tão frequentemente posta, mas sim preenchidos de valores, interesses, intencionalidades e intervenções físicas no mundo bastante diferenciadas (LAYRARGUES , 2011, p. 80).

Isso nos traz a compreensão de que os impactos ambientais não são causados pela humanidade de forma genérica, como se todos/as tivessem a mesma responsabilidade e todos/as sofressem os mesmos impactos, mas que as relações de produção, os meios de produção e as relações de trabalho determinam quem acumula as riquezas geradas pelo trabalho, quem será explorado vendendo seu trabalho e quem sofrerá os impactos negativos do usufruto da natureza.

Lowy (1975) aponta que as relações de trabalho, de produção e de apropriação comum da natureza são os responsáveis pela antropogênese, um fenômeno de caráter intrinsecamente social que põe o ser humano no centro do debate de dominação. O que determina uma estrutura organizacional da sociedade e, dessa forma, a própria consciência dos seres humanos, já que ela não é somente individual, mas está em conexão com toda a sociedade na qual está inserida.

A compreensão da categoria totalidade também se faz necessária a uma Educação Ambiental que pretende discutir os problemas ambientais a partir da unidade da diversidade. Ela existe tal como na realidade, sendo um elemento constitutivo do real que se organiza como totalidade.

Hungaro (2014) afirma que a totalidade está na realidade concreta, não se tratando de conhecer os vários aspectos que a compõe, mas de perceber que são a mesma coisa. Assim, à Educação Ambiental crítica cabe reproduzir idealmente o que está posto na crise ambiental, em suas múltiplas dimensões que compõem a totalidade/realidade, a ética, a estética, a natural, a social, a cultural, a política, a ideológica e a tecnológica.

Trazer a totalidade para a Educação Ambiental crítica prediz compreendê-la como um todo estruturado, em sua multidimensionalidade. Como sendo um 
[...] sistema organizado por relações e fluxos, que em sua dinâmica dão o sentido de permanência (organização e nexos lógicos) e de desordem (movimento de construção contínuo e indissociável entre todo e partes, sendo que cada parte é uma totalidade inserida em outras (totalidades). Significa racionalmente compreender que o singular ganha sentido em suas relações (totalizações) e que o todo é mais que a soma das singularidades, num movimento de mútua constituição (LOUREIRO, 2011, p. 147-148).

Ainda enquanto categoria presente na Educação Ambiental crítica, a práxis se estabelece como uma atividade concreta, não tecnicista ou instrumental, cujos/as envolvidos/as em sua prática, através da reflexão na ação, se afirmam no mundo, conhecendo e reconhecendo os problemas existentes em suas realidades e sendo modificados/as por essa reflexão e essa ação, na relação da teoria com a prática (KONDER, 2014).

A práxis implica ação e reflexão dos indivíduos envolvidos nas práticas educativas, de forma que essa reflexão recaia sobre o mundo que antecede e se materializa nas suas palavras e consciências para poder transformá-las, como bem coloca Freire (2016). Essa reflexão parte da experiência imediata dos dados da vida social, construindo de forma abstrata um sistema de ideias e representações sobre a realidade. Implica ainda entender que o processo de emancipação humana está atrelado à superação da alienação causada pelas ideologias, e isso ocorre através da tomada de consciência.

Para superação disso, como nos aponta Lowy (1975), essa práxis precisa ser revolucionária. Deve perfazer-se ao mesmo tempo causa e efeito de um processo histórico cuja humanidade faz a sua história. Assim, a mudança das circunstâncias da realidade concreta das crises ambientais coincide com a transformação (subjetiva) da humanidade.

Trazer essa compreensão das bases ontológicas da Educação Ambiental crítica e das categorias presentes em suas discussões, significa compreender a emancipação enquanto teleologia desse processo. É acreditar, assegurar e fomentar que a finalidade da Educação Ambiental, para além da sensibilização da humanidade quanto ao restante da natureza, seja a promoção de cidadania e de um pensamento democrático absoluto, não desatrelado dos problemas ambientais, dos sociais, dos políticos, dos éticos, dos culturais e dos ideológicos.

A Educação Ambiental crítica, que tem como finalidade a emancipação humana, surge então como uma filosofia que busca reorientar as premissas do pensar e do agir humano na perspectiva de transformação das situações concretas e limitantes de melhores condições de vida dos sujeitos. Age, portanto, como um horizonte de construção de conhecimentos e práticas que proporcionem a todos os sujeitos envolvidos uma intervenção crítica na realidade (FERRARI; MAESTRELLI; TORRES, 2014). 
Assim, para construção de propostas educativas emancipatórias, eticamente comprometidas com a humanização, é fundamental um processo em que todo o desenvolvimento da vida humana - necessidades, conflitos, tensões, contradições econômicas e ambientais - seja o ponto de partida para a reflexão e construção de uma consciência capaz de subsidiar a transformação da realidade (PERNAMBUCO; SILVA, 2014).

Essa conscientização, advinda da reflexão e da ação dos próprios sujeitos, não consiste em somente estar diante da realidade, assumindo uma posição ingênua, como nos adverte Freire (2016), uma vez que ela não pode se realizar fora da práxis. A conscientização implica que essa posição diante da realidade saia da esfera espontânea de apreensão da mesma, para uma esfera crítica. Isso requer objetivar esse processo. Exige que os/as participantes que estão envolvidos/as na prática social da Educação Ambiental crítica sejam capazes de atuar conscientemente sobre a realidade. Não como uma abordagem puramente comportamentalista, mas na unidade indissociável entre a ação e a reflexão sobre o mundo. De forma que:

É preciso ficar claro que a consciência ou a intencionalidade da consciência não se esgota ou se exaure na racionalidade do ser. A consciência do mundo que implica a consciência de mim no mundo, com ele e com os outros, que implica também a nossa capacidade de perceber o mundo, de compreendê-lo, não pode ser reduzida a uma experiência racionalista. É como uma totalidade - razão, sentimentos, emoções, desejos, que meu corpo consciente do mundo e de mim capta o mundo a que se intenciona (FREIRE, 2013, p. 132).

Nesse sentido, quanto mais crítica a Educação Ambiental for, mais democrática ela será, e ainda mais permeável. E, sendo democrática, será mais ligada às condições da realidade/totalidade na qual está inserida, junto a seus/as participantes. Freire (2002) adverte ainda que quanto menos democrática for essa prática, mais superposta serão suas discussões e mais inclinadas a formas ingênuas de encarar o mundo.

Para se alcançar emancipação através da conscientização na Educação Ambiental crítica, parafraseando Freire (2016), é preciso que os homens e mulheres se tornem os sujeitos que se constroem enquanto pessoas que transformam o mundo, que descubram que podem fazê-lo. Que firmem relações de reciprocidade uns com os outros, que formem sua própria cultura e façam a sua história através da participação. Portanto, é primaz fazer da conscientização o objetivo fundamental da prática educativa. É preciso provocar atitudes críticas de reflexão que levem à ação e na ação.

Assim, em uma práxis de libertação, os/as que são conscientizados/as do seu lugar no mundo e de que podem mudá-lo, tomam posse da própria realidade na qual o mundo se apresenta, reconhecem-se nela enquanto seres 
sociais que constroem essa história e se inserem na mesma com a finalidade de transformá-la. Realizando dessa forma a finalidade para a qual a própria Educação Ambiental crítica se propõe: a emancipação humana.

\section{Da dialética, da complexidade e da transdisciplinaridade na Educação Ambiental}

Na perspectiva de uma prática social educativa que visa à emancipação, a Educação Ambiental crítica necessita se apoiar na dialética existente nas relações que a perpassam. Dentro da visão totalizante e concreta da realidade, a formação humana e a social só poderão ser concebidas enquanto o conjunto das relações existentes na humanidade, entre a humanidade e a natureza em desenvolvimento, no devir, produzida historicamente pela relação através do trabalho e da práxis, na compreensão da complexidade e da totalidade.

Para se alcançar esse processo educativo, a educação imersa na dimensão ambiental de forma crítica necessita, além da transposição do caráter disciplinar, incorporar a complexidade da totalidade no mesmo nível dos problemas ambientais. Ela precisa assumir um pensamento sistêmico no processo de construção dos conhecimentos e saberes ambientais, reconhecendo a dialética nas contradições e tensões existentes tanto nas relações do ser humano com a natureza quanto dos seres humanos entre si com as práticas educativas desses processos. $E$ tudo isso em um movimento real de complementação que impulsiona uma transformação ou conservação da realidade (LEFF, 2003).

Pensar uma Educação Ambiental que considera essas relações dialéticas em suas práticas, perpassa as três leis apontadas por Engels (1968): a lei da transformação da quantidade em qualidade e vice-versa; a lei da interpenetração dos contrários; e a lei da negação da negação.

Para além de considerar os aspectos biológicos, físicos e químicos da natureza, o próprio Engels (1968) já sinalizava que essas eram leis gerais aplicáveis tanto ao desenvolvimento do mundo natural quanto da sociedade e do pensamento. Dessa forma, a Educação Ambiental crítica, enquanto prática social orientada a transformar a natureza e a vida social, caminha na perspectiva de que as mudanças quantitativas de diminuição das desigualdades, de equiparação nas injustiças (sociais e ambientais), de democratização absoluta e participação em todos os processos sociais (de tomadas de decisões à aplicação de metas) originam mudanças qualitativas necessárias ao equilíbrio do meio ambiente, à conscientização e à mudança de atitudes diante do mundo.

A Educação Ambiental crítica considera ainda a interpenetração das contradições internas e externas à Educação Ambiental, a relação do ser humano com o mundo natural, da sociedade com a natureza, dos problemas ambientais com os sociais, na compreensão de que os diversos aspectos da realidade se entrelaçam e que essas forças contraditórias e a elucidação de 
suas raízes podem impulsionar as mudanças necessárias. Requer também o entendimento de que essas relações não se esgotam em contradições sem significados ou simplesmente na eterna negação do que está posto, mas, como aponta Konder (2014):

[...] dá conta do fato de que o movimento geral da realidade faz sentido, quer dizer, não é absurdo, não se esgota em contradições irracionais, ininteligíveis, nem se perde na eterna repetição do conflito entre teses e antíteses, entre afirmações e negações. A afirmação engendra necessariamente a sua negação, porém a negação não prevalece como tal: tanto a afirmação como a negação são superadas e o que acaba por prevalecer é uma síntese, é a negação da negação (KONDER, 2014, p. 57).

Essas contradições, que não são sem significado, prevalecem hoje no mundo e estabelecem relações desarmônicas entre a humanidade e dela com a natureza. Como afirma Guimarães (2011), são construídas historicamente pela sociedade moderna. Assim, cabe à Educação Ambiental crítica partir dessas próprias contradições, que não são especificamente naturais, mas, acima de tudo, sociais, estabelecidas entre as classes e setores diversos, e trazer à luz discussões de suas teses e antíteses para que se encontrem as soluções. $E$ isso se faz por meio da participação e do engajamento.

Loureiro (2011) expõe ainda que a superação dialética daquilo que se mostra inadequado pressupõe o entendimento do que se está negando a partir da constante construção coletiva dos saberes, da aprendizagem e do próprio conhecimento através de ações políticas, individuais e coletivas que visem à transformação social.

Nesse sentido, torna-se importante também compreender a complexidade que a totalidade dos fenômenos abrange em seus aspectos contraditórios em sua multidimensionalidade, na unidade que existe nessa diversidade, na práxis existente da reflexão na ação, nas incertezas e na utopia presente na Educação Ambiental crítica.

Leff (2008) aponta que para pensar e conceber o ambiente através da complexidade que ele abrange, carregado de subjetividades, é necessária uma construção coletiva de uma racionalidade não acabada, de uma dimensão não neutra e nem homogênea, na transcendência para a alteridade e diferença, na transição para a sustentabilidade e a justiça.

Requer ainda a superação dos reducionismos normalmente encontrados nas práticas de Educação Ambiental, os quais se resumem à sensibilização e pactos comportamentalistas quanto aos problemas determinados como urgentes. Para a Educação Ambiental crítica, é fundamental que esteja impregnada em suas práticas não apenas a declaração da importância de 
mudanças e de busca de harmonia, como afirma Loureiro (2011), mas de ações e intencionalidade de todos/as os/as indivíduos envolvidos/as, alterando as subjetividades e construindo práticas políticas de transformação das condições objetivas existentes.

No contexto da complexidade, para a efetivação dessas ações, é preciso ter a consciência das incertezas que o permeiam, deixando claro, como aponta Morin (2015), que não existe de um lado um campo da complexidade, perfazendo pensamento e reflexão e do outro, a própria ação. A ação assim vem a ser o concreto e o vital da complexidade; o que garante a qualidade da práxis educativa, a própria relação dialética entre a ação e a reflexão.

É preciso que haja a superação do organicismo, visto que enxerga o todo como uma organização complexa, porém, em uma totalidade harmoniosa. Ou ainda o holismo, que acredita ser a totalidade a soma de todas as coisas. Nessa relação da complexidade da totalidade, é importante destacar as próprias contradições que a compõem, assim como a compreensão de que a soma de suas partes não significa necessariamente o todo. Mas que a totalidade é formada pelo complexo de outras partes totais.

Assim, pensar a complexidade ambiental dentro das práticas educativas, requer uma prática pedagógica política de dialogicidade no ensino e aprendizagem, que seja significativa no que Leff (2003, p. 10) chama de "construção plural de sujeitos e atores sociais capazes de abrir as possibilidades para a recriação de mundos alternativos, guiados pelos valores da democracia e os princípios da sustentabilidade".

Implica em uma revolução do pensamento e do ensino; o que Morin (2018) considera como uma reforma em uma relação recursiva, em que um atua sobre o outro e, concomitante, através da transformação das subjetividades, impacta em reformar também a escola e a sociedade.

Essa relação complexa e dialética de mudar o pensamento e o ensino (subjetividades), mas também a própria educação e a sociedade (coletividade), encontra ressonância na fala de Loureiro (2011):

[...] é insuficiente querer mudar o indivíduo sem mudar a realidade social em que este se situa como sujeito. É simplista, linear e dicotômico achar que a sociedade é um desdobramento direto da soma das esferas pessoais, sem relações de construção multidirecional, numa formulação que peca pela falta de dialética entre parte-todo e que reforça o projeto neoliberal de sociedade (LOUREIRO, 2011, p. 109).

$\mathrm{Na}$ insuficiência de posturas e críticas aos aspectos ambientais isolados, sem considerar a complexidade de sua totalidade, o autor ainda afirma: 
O resultado de tal ordem de reducionismo, além de possibilitar abordagens lineares, politicamente conservadoras e reacionárias, é pensar e procurar resolver o equilíbrio da espécie no ecossistema, ignorando o desequilíbrio dos indivíduos e dos grupos e classes que condicionam o próprio modo como interagimos com a natureza (LOUREIRO, 2011, p. 120).

Essa compreensão do mundo e do ambiente como uma totalidade que abarca a complexidade de outras totalidades, traz para a Educação Ambiental crítica a responsabilidade de integrar os diferentes aspectos e níveis da materialidade que compõe o meio ambiente e suas interfaces da crise planetária. Requer ainda a articulação do conhecimento, dos saberes e das tecnologias que são produzidas nessas ordens diferenciadas, para dar conta das mudanças necessárias (LEFF, 2003).

Leff (2003) ressalta ainda que para a Educação Ambiental, enquanto uma prática social que visa à transformação das subjetividades e da sociedade diante da natureza, é necessária uma pedagogia da complexidade ambiental, com práticas que permitam a educação atuar como um espaço de construção de uma nova racionalidade, em que esta não se vincula a uma cultura de desesperança e alienação. Pelo contrário, deve imperar uma racionalidade que promova uma cultura de processo de constante emancipação humana, que permita aos indivíduos não só se reconhecerem no mundo e o mudarem, mas também a própria reapropriação dele.

Pensar essa educação que busca considerar a multirreferencialidade e a multidiversidade que abrangem o campo ambiental, com todos os seus aspectos e fatores permeados de questões naturais, sociais, culturais, tecnológicas, éticas, estéticas e políticas, torna-se fundamental romper com as barreiras disciplinares que se apresentam no horizonte dessa prática.

A Política Nacional de Educação Ambiental - PNEA (Lei 9795/99), seguindo outros documentos oficiais internacionais, dos quais o Brasil é signatário, dispõe em seu Artigo 10 que a Educação Ambiental deve ser desenvolvida como uma prática educativa integrada, contínua e permanente em todos os níveis e modalidades do ensino formal, especificando que a mesma não deve ser implantada como disciplina específica, exceto em cursos de pós-graduação, extensão e em áreas voltadas ao seu aspecto metodológico. Nos cursos de formação de professores/as, a lei especifica que deva constar em seus currículos a dimensão ambiental.

Em especial, essas características necessitam ser discutidas e repensadas, tendo em vista que os/as professores/as tenderão a apresentar discussões em suas práticas docentes advindas da sua formação inicial, ficando relegado, assim, aos/às próprios/as professores/as se dedicarem a buscar os conhecimentos e saberes necessários à prática educativa ambiental de forma autônoma ou através de formação complementar. 
A PNEA, em seu Artigo 8, parágrafo terceiro, apresenta também que as ações de estudos, pesquisas e experimentações devam voltar-se para o desenvolvimento de instrumentos e metodologias de forma interdisciplinar. Apresenta ainda a busca de alternativas curriculares e metodológicas de capacitação na área ambiental. Aqui encontramos a abertura organizacional sobre a qual procuramos refletir.

Para além da problemática já apresentada da inexistência de um componente curricular que trabalhe a Educação Ambiental em toda a sua complexidade, fica relegado aos/às professores/as que esses/as, além de precisar buscar formação e informação por conta própria, dialoguem entre si, cada um na sua área, com as temáticas e problemas ambientais existentes.

A própria grandeza do cientificismo moderno acabou por fragmentar toda a realidade, relegando a especialistas que discutam, a partir da sua área - e somente dela -, o ponto de vista de qualquer assunto. O que se apresenta, nas palavras de Nicolescu (1999), como a própria decadência do cientificismo. Decadência, nesse caso, porque não permite nem ao/à professor/a em formação ter a compreensão da totalidade da realidade e da problemática ambiental existentes, nem aos sujeitos que estarão envolvidos na aprendizagem durante a prática docente desses/as professores/as em formação.

Nesse sentido, a transdisciplinaridade surge da reivindicação de um diálogo entre os saberes e conhecimentos científicos que, mesmo existindo a delimitação dos campos disciplinares, suas barreiras se rompem para que o tema transversal (nesse caso o meio ambiente) possa ser discutido e refletido sob um olhar de pluralidade complexa, cujo diálogo entre as ciências se torna mais profundo, havendo uma transmigração de conceitos fundamentais (ASSMANN, 1998).

Assim, a Educação Ambiental na formação inicial de professores/as surgiria como um projeto comum que se perpassa nas suas formações, mas também nas suas práticas docentes, na forma ecodisciplinar e metadisciplinar, como propõe Morin (2018), em que as disciplinas se apresentam plenamente justificáveis, mas desenvolvem uma visão que reconhece e cria o intercâmbio, a cooperação e a policompetência.

A Educação Ambiental, enquanto tema transversal que deve estar presente em todos os níveis e modalidades de ensino, precisa adequar-se à perspectiva de uma abordagem transdisciplinar, pelo fato desta dizer respeito:

[...] àquilo que está ao mesmo tempo entre as disciplinas, através das diferentes disciplinas e além de qual disciplina. Seu objetivo é a compreensão do mundo presente, para o qual um dos imperativos é a unidade do conhecimento (NICOLESCU, 1999, p. 53). 
Do ponto de vista do pensamento positivista, do cartesianismo, da modernidade e da fragmentação do saber, não haveria qualquer coisa entre nem através das disciplinas ou do conhecimento científico. Porém, à luz da dialética, a qual considera o contraditório e a unidade na diversidade, e segundo a complexidade, que considera a totalidade da realidade concreta e a multirrefencialidade dos aspectos envolvendo o meio ambiente e a Educação Ambiental, a transdisciplinaridade se apresenta como um novo paradigma para o pensamento, o ensino, o currículo, o planejamento e a ciência, sendo capaz de viabilizar os objetivos de uma Educação Ambiental que se pretende crítica, transformadora e emancipatória.

\section{Formação inicial de professores/as e a Educação Ambiental crítica}

A Educação Ambiental crítica, enquanto prática social e tendo como teleologia a emancipação humana, a qual considera a dialética e a complexidade da/na dimensão ambiental inserida na educação com a perspectiva da transdisciplinaridade, compreende a necessidade de reconhecer que a formação inicial de professores/as começa pela construção dos Planos Pedagógicos dos Cursos (PPC). Este campo do currículo assimila e concebe ideologias e utopias que podem servir para conservar o status quo da formação humana através da educação ou para fomentar transformações iniciadas na mesma.

Em sociedades divididas entre os que detêm, dominam e exploram tanto a natureza quanto a própria humanidade a fim de produzir e acumular riquezas e transferir os danos ambientais aos/às dominados/as, suas ideias e representações são produzidas e difundidas pela classe dominante através de todos os aparelhos sociais dos quais se possam alcançar as massas e, assim, legitimar e assegurar seus poderes econômicos, sociais e políticos.

Chauí (2012) adverte que essas ideias e representações (ideológicas) tendem a esconder do restante da sociedade o modo real como as relações sociais foram produzidas e a origem das formas de exploração, de espoliação, de dominação econômica, política, social e ambiental. Dessa forma, ideologicamente, aqueles que dominam os meios sociais, econômicos e ambientais legitimam as condições existentes fazendo com que pareçam verdadeiras e justas.

O currículo, enquanto documento oficial e norteador de um programa ou curso, é um campo fértil e eficaz para implementação dessas ideologias dominantes, uma vez que, como afirma Apple (2006), o mesmo finca suas raízes no próprio solo do controle social. Partindo do pressuposto de que o currículo se perfaz como um conjunto de procedimentos, visto que seleciona e organiza o conhecimento escolar, o mesmo carrega os interesses, os valores, as crenças e as ideias daqueles/as que o constroem em um determinado tempo e contexto socio-histórico-cultural. 
Dessa forma, o currículo vem a ser um campo onde, a partir do contexto no qual foi construído, as ideologias presentes na sociedade ou as utopias necessárias à transformação da realidade são colocadas em prática para permear a formação humana. Nesse sentido, de uma Educação Ambiental que se propõe à emancipação, o currículo pode se tornar um campo de atuação para além da reprodução ideológica, indo ao encontro do que Apple (2006) chama de enfrentamento da realidade, proporcionando a todos/as envolvidos/as em sua execução não só a orientação nas questões econômicas, legais e culturais de grupos oprimidos social e ambientalmente, como também a participação e a promoção da democracia e da cidadania.

Currículos que se pretendem emancipadores pressupõem tanto a sua concepção como a sua gestão de forma democrática, tendo como objetivo a inclusão, o compromisso social e, no caso da Educação Ambiental crítica, o desnudamento das ideologias que perpetuam as situações de exploração da natureza e da humanidade, comportando utopias que são irresignáveis. Desse modo,

[...] são democráticos em seus princípios e propósitos, integradores e tolerantes com as diferenças (transculturais), universalistas em sua intenção e abrangência (transnacionais), para estender a todos os indivíduos (que são sociais) condições concretas de autonomia política, econômica e intelectual. A educação para liberdade precisa dar-se no bojo de um processo global de emancipação, no qual a virtualidade do conflito está sempre presente (DE ROSSI, 2004, p. 30).

Assim, para a Educação Ambiental crítica na formação inicial de professores/as, é essencial que o próprio currículo, ou seja, os PPC desses cursos sejam construídos de forma contextualizada com as utopias necessárias ao enfrentamento da realidade e das problemáticas sociais e ambientais existentes. É necessário que eles possam contribuir para espaços cujas participação e democracia sejam não somente finalidades da sua execução, mas também o próprio processo de execução, contribuindo com práticas sociais e educativas comprometidas em atingir seus propósitos e intencionalidades.

Um currículo, como Apple (2006) afirma, que proporcione outras maneiras de ação e de reflexão, capazes de levantar questionamentos importantes para a realidade apresentada; que incentive e conduza também ao engajamento coletivo, não somente daqueles/as que fazem parte da sua concepção, mas de todos(as) envolvidos/as em sua execução.

Uma outra preocupação para a Educação Ambiental crítica na formação inicial de professores/as diz respeito às práticas pedagógicas que se pretendem construir nessa formação. Em como esses/as futuros/as professores/as atuarão em suas práticas docentes. E isso envolve desde o 
planejamento de suas atividades e execução até a avaliação do processo de ensino e aprendizagem.

A Educação Ambiental crítica requer da formação inicial de professores/as discussões e a construção de práticas pedagógicas que ultrapassem as perspectivas normativas de treinamento linear, a fim de que alcancem uma perspectiva dialética; uma práxis que sustente as práticas docentes desses(as) futuros(as) profissionais em um diálogo contínuo entre os sujeitos e as suas circunstâncias; uma ação consciente e participativa, como afirma Franco (2016), considerando a multidimensionalidade que cerca o ato educativo.

As práticas pedagógicas de uma Educação Ambiental crítica requerem a intencionalidade da incorporação da reflexão contínua e coletiva e a racionalidade de que a historicidade é condição para compreensão do conhecimento e da realidade concreta sobre os problemas ambientais e sua multidimensionalidade. Nesse sentido,

[...] a prática pedagógica realiza-se por meio de sua ação científica sobre a práxis educativa, visando compreendê-la, explicitá-la a seus protagonistas, transformá-la mediante um processo de conscientização de seus participantes, dar-lhe suporte teórico, teorizar com os atores, encontrar na ação realizada o conteúdo não expresso das práticas (FRANCO, 2012, p. 169).

Essas práticas, na Educação Ambiental crítica, contribuem para a explicitação do que está posto no mundo e as formas como todos/as envolvidos/as na prática educativa podem se reconhecer diante dele para a negociação de uma intencionalidade coletiva que, conforme Gilberto e Franco (2017), dirige e dá sentido às ações individuais e coletivas.

Práticas educativas críticas contribuem para o conhecimento do objeto e da realidade que se quer transformar, dentro de uma direção de intencionalidade organizada de forma coletiva, assim como para a intervenção planejada sobre a problemática que se apresenta. Nesse caso, auxiliando a Educação Ambiental crítica com a finalidade de transformar as ações e concepções dos/as indivíduos envolvidos/as.

Gilberto e Franco (2017) alertam que, para a construção dessas práticas pedagógicas, é necessário abertura para o diálogo coletivo e para a reinterpretação das próprias práticas docentes, no caso da formação inicial de professores/as, das próprias concepções que os/as mesmos/as carregam sobre como devem ser suas práticas e também das ações desses/as indivíduos no mundo. Os autores ainda refletem que 
essa experiência formativa pressupõe também uma abertura para o querer-saber-quem-sou como professor e pensar nas significações que essas ações implicam para que o desejo de transformar-(se) se realize, considerando que cada prática é diferenciada e complexa. E mais: que a sala de aula, mesmo aquela situada na mais longínqua escola rural, é parte de um todo complexo, múltiplo e diversificado (GILBERTO; FRANCO, 2017, p. 24).

Dessa forma, a compreensão da necessidade de práticas pedagógicas críticas na formação inicial de professores/as contribui para pensar a complexidade da dimensão ambiental na educação, considerando a necessidade da conscientizar o ser humano diante do mundo e de como este pode intervir nele, e ainda da própria consciência subjetiva e coletiva do inacabamento dessa conscientização, de sua emancipação humana enquanto sujeito que é social e natural e da sua responsabilidade na formação de sujeitos críticos e ambientalmente conscientes.

Franco (2016) alerta que essa prática pedagógica crítica está profundamente relacionada aos aspectos multidimensionais que perpassam a realidade, a construção histórica das subjetividades, do coletivo e as determinações que medeiam as práticas docentes. De forma que é uma prática que é executada através da intencionalidade com planejamento, acompanhamento, vigilância crítica e responsabilidade social.

Exatamente o que não se pode faltar a uma prática educativa imersa na dimensão ambiental, visto que busca auxiliar os indivíduos, fomentando transformações necessárias de atitudes, concepções e percepções, diante um mundo que se encontra em profunda crise ambiental, social, econômica, ética, cultural e estrutural.

A Educação Ambiental crítica requer um currículo e uma formação que caminhem com práticas pedagógicas produtoras e promotoras de reflexões críticas sobre as práticas docentes e a consciência das intencionalidades que regem essas práticas. É preciso considerar se essas estão servindo à conservação do que está posto ou se auxiliam para mudanças.

Esses requisitos, na formação inicial de professores/as, contribuem para a inserção da Educação Ambiental crítica em indivíduos que serão essenciais à formação humana. E esta deve se efetivar sob perspectivas de emancipação, de conscientização, de transformação da realidade e de superação das ideologias, as quais se mitificam nos processos e nas práticas sociais, de modo a conservar o que está posto.

Para esse tipo de ação educativa de caráter formativo, Imbernón (2016) defende que os/as professores/as são atores e atrizes essenciais na intermediação e promoção de construção de conhecimentos através dessas perspectivas e de uma educação de qualidade. Uma qualidade que tenha como 
meta a cidadania democrática através de saberes, procedimentos e atitudes que permitam participação na criação de um mundo melhor.

Imbernón (2011) defende também que é necessário estabelecer um preparo na formação inicial desses/as professores/as, para que lhes sejam proporcionados conhecimentos válidos, gerando atitudes interativas e dialéticas de criação de métodos interventivos de cooperação, análise e reflexão, convivendo com as próprias limitações e com a realidade dos seus contextos. $\mathrm{O}$ que requer um comprometimento com o próprio contexto histórico, cultural e social no qual esses/as professores/as em formação estão inseridos/as. E reafirma:

Os futuros professores e professoras também devem estar preparados para entender as transformações que vão surgindo nos diferentes campos e para ser receptivos e abertos a concepções pluralistas, capazes de adequar suas atuações às necessidades dos alunos e alunas em cada época e contexto. (IMBERNÓN, 2011, p. 64).

Sem essa compreensão clara das contradições existentes na realidade, da dialética, da complexidade e da totalidade na formação inicial de professores/as, dificilmente esses/as irão atuar em suas práticas docentes de forma a reconhecer a pluralidade de ideologias e utopias presentes, de modo a agir de forma democrática, participativa e engajada, na busca das brechas dentro da realidade que podem impulsionar transformações subjetivas e coletivas.

Imbernón (2012) adverte ainda que a realidade social e científica demonstra o quanto a formação docente é complexa e não uniforme, caracterizando-se eminentemente contextual. Assim, a própria formação docente deve agir sobre esses/as futuros/as profissionais a partir de seus contextos, observando os processos de comunicação, os estruturais, os políticos, de relação de poder, de tomada de decisões e de autonomia compartilhada, garantindo dessa forma que quaisquer discussões possam se estabelecer no campo da dialogicidade, da reflexão na ação e da compreensão de si e do mundo.

Uma formação dessa natureza requer desses/as professores/as a compreensão da impossibilidade de neutralidade da educação, a qual Freire (1996, p. 112), com muita propriedade, afirma que "se a educação não pode tudo, alguma coisa fundamental a educação pode". O que demanda, como o próprio autor afirma, a lucidez de que a educação, enquanto prática social, mesmo sendo crítica, não é uma força imbatível que irá mudar a realidade sozinha, mas que, submergida em utopias não ingênuas, tampouco é a perpetuação do status quo. 


\section{Conclusões}

A Educação Ambiental crítica na formação inicial de professores/as, que apresenta como teleologia a emancipação humana, contribui para a preparação de profissionais que atuarão na sociedade na busca de compreender as contradições existentes nas problemáticas ambientais e sociais e promover reflexões que conduzam os/as indivíduos a reconhecerem suas atitudes diante do mundo.

Nesse intuito, é primaz que estejam presentes não somente nas discussões ambientais, como também na própria formação docente, a dialética da ontologia do ser social, que também é natural, e suas concepções de mundo, as quais interferem e ressoam no modo como os indivíduos se reconhecem na natureza e agem nela e nas suas próprias comunidades.

É solícito que as categorias que perfazem o fazer educativo na perspectiva crítica e na própria relação da humanidade com a natureza sejam desveladas e apropriadas por todos/as os/as professores/as em formação. A compreensão de que as relações de trabalho afetam diretamente as relações de produção e de consumo e as sociais e ambientais se torna irresignável para o entendimento da multidiversidade dos aspectos ambientais e da complexidade da totalidade da crise ambiental.

Nesse sentido, repensar como a Educação Ambiental se apresenta em todos os níveis e modalidades de ensino e, em especial, na capacitação inicial de professores/as que promoverão formação humana, enseja refletir sobre quais referenciais teóricos ela vem se pautando. Pensar em como é executada nas práticas educativas e de que modo pode ser trabalhada entre os componentes curriculares de forma que não recaia em mais diálogos superficiais, reducionistas e isolados.

A dialética presente nas relações sociedade e ambiente, ser humano e natureza, aspectos sociais e naturais, é um desses pressupostos para se (re)pensar a Educação Ambiental crítica na formação docente. Junto a isso, a compreensão da complexidade da totalidade, visto que se estabelece a partir de outras totalidades também complexas e em uma unidade na diversidade, a qual se faz presente.

Para além do trabalho isolado de cada disciplina sobre a temática ambiental, é fundamental romper com as barreiras disciplinares, mesmo sendo bem estabelecidas, e caminhar em diálogos profícuos sobre os aspectos ambientais, de forma que o centro do debate seja como os conhecimentos contribuem para o enfretamento à crise ambiental.

(Re)pensar a Educação Ambiental na formação docente exige ainda o reconhecimento do espaço curricular e das práticas pedagógicas desenvolvidas nessa formação. Enquanto área de atuação política não neutra, o currículo pode servir de conservação das ideologias dominantes e de reprodução de uma sociedade dividida em classes, que dominam a natureza e 
a si próprias, assim como pode ser um campo de utopias necessárias à transformação da realidade.

Da mesma forma, as práticas que se desenvolvem nessa formação podem estabelecer a intencionalidade relacional do contexto histórico-culturalsocial, de reflexão na ação necessária às mudanças subjetivas e coletivas que se esperam. $\mathrm{E}$ isso demanda uma formação docente que promova participação, colaboração, engajamento, democracia e cidadania.

$\mathrm{Na}$ compreensão de que seria ingênuo acreditar em uma Educação Ambiental crítica capaz de, por si só, mudar ações e concepções de professores/as e da sociedade, a mesma se apresenta como resistência ao status quo, porque busca a superação das dominações, da exploração e da espoliação que há entre a humanidade e a natureza.

\section{Referências}

ALMEIDA, J. P. Formação docente para a promoção da Educação Ambiental: o caso de uma escola estadual em Maceió (AL). Revista Brasileira de Educação Ambiental, Rio Grande, V. 8, № 1: 114-129, 2013.

APPLE, M. Ideologia e currículo. 3. ed. Porto Alegre: Artmed, 2006.

ASSMANN, H. Reencantar a educação: rumo à sociedade aprendente. 2. ed. Petrópolis: Vozes, 1998.

BRASIL. Lei no 9.795, de 27 de abril de 1999. Política Nacional de Educação Ambiental. Brasília, DF: Presidência da República, [2020]. Disponível em: http://www.planalto.gov.br/ccivil 03/leis//9795.htm>. Acesso em: 28 de novembro de 2020.

CHAUÍ, M. O que é ideologia. São Paulo: Brasiliense, 2012.

DE ROSSI, V. L. Gestão do Projeto Político Pedagógico: Entre corações e mentes. São Paulo: Moderna, 2004.

ENGELS, F. Dialética da natureza. Rio de Janeiro: Editora Leitura, 1968.

FERRARI, N.; MAESTRELLI, S. R. P.; TORRES, J. R. Educação Ambiental crítico-transformadora no contexto escolar: teoria e prática freireana. In: Educação Ambiental: dialogando com Paulo Freire. LOUREIRO, C. F. B.; TORRES, J. R. (Orgs.). São Paulo: Cortez, 2014.

FRANCO, M. A. R. S. Pedagogia e prática docente. São Paulo: Cortez, 2012.

FRANCO, M. A. R. S. Prática pedagógica e docência: um olhar a partir da epistemologia do conceito. Revista Brasileira de Estudos Pedagógicos, Brasília, V. 97, n. 247, p. 534-551, set. /dez. 2016.

FREIRE, P. À sombra desta mangueira. 11. ed. Rio de Janeiro: Paz e Terra, 2013.

FREIRE. P. Conscientização. São Paulo: Cortez, 2016. 
FREIRE, P. Educação como prática da liberdade. 26. ed. Rio de Janeiro: Paz e Terra, 2002.

FREIRE, P. Pedagogia da autonomia: saberes necessários à prática educativa. São Paulo: Paz e Terra, 1996.

GILBERTO, I. J. L.; FRANCO, M. A. R. S. O observatório da prática docente como espaço de reflexão sobre o currículo e os desafios das práticas. In: Práticas pedagógicas: pesquisa e formação. FRANCO, M. A. R. S.; GILBERTO, I. J. L.; CAMPOS, E. F. E. (Orgs.). São Paulo: Edições Loyola, 2017.

GUIMARÃES, M. Armadilha paradigmática na Educação Ambiental. In: Pensamento complexo, dialética e Educação Ambiental. CASTRO, R.S.; LOUREIRO, C. F. B.; LAYRARGUES, P. P. (Orgs.). 2.ed. São Paulo: Cortez, 2011.

HUNGARO, E. M. A questão do método na constituição da teoria social de Marx. In: $O$ método dialético na pesquisa em educação. CUNHA, C.; SOUSA, J. V.; SILVA, M. A. (Orgs.). Campinas, SP: Faculdade de Educação, Universidade de Brasília, UnB, 2014.

IMBERNÓN, F. Formação docente e profissional: formar-se para a mudança e a incerteza. 9. ed. São Paulo: Cortez, 2011.

IMBERNÓN, F. Inovar o ensino e a aprendizagem na universidade. São Paulo: Cortez, 2012.

IMBERNÓN, F. Qualidade do ensino e formação do professorado: uma mudança necessária. São Paulo: Cortez, 2016.

KONDER, L. O que é dialética. São Paulo: Brasiliense, 2014.

LAYRARGUES, P.P. Muito além da natureza: Educação Ambiental e reprodução social. In: Pensamento complexo, dialética e Educação Ambiental. CASTRO, R. S.; LOUREIRO, C. F. B.; LAYRARGUES, P. P. (Orgs.). 2.ed. São Paulo: Cortez, 2011.

LEFF, E. Pensar a complexidade ambiental. In: A complexidade Ambiental. LEFF, E. (coord.). Tradução de Eliete Wolff. São Paulo: Cortez, 2003.

LEFF, E. Saber ambiental: sustentabilidade, racionalidade, complexidade, poder. 6. ed. Petrópolis, RJ: Vozes, 2008.

LOUREIRO, C. F. B. Educação Ambiental: questões de vida. São Paulo: Cortez, 2019.

LOUREIRO, C. F. B. Problematizando conceitos: contribuição à práxis em Educação Ambiental. In: Pensamento complexo, dialética e Educação Ambiental. CASTRO, R. S.; LOUREIRO, C. F. B.; LAYRARGUES, P. P. (Orgs.). 2.ed. São Paulo: Cortez, 2011. 
LOWY, M. Método dialético e teoria política. Tradução de Reginaldo Di Piero. Rio de Janeiro: Paz e Terra, 1975.

LUKACS, G. Para uma ontologia do ser social. 2. ed. São Paulo: Boitempo, 2018.

MARX, K. O Capital: crítica da economia política. 2.ed. Tradução de Regis Barbosa e Flávio R. Kothe. São Paulo: Nova Cultural, 1985.

MORIN, E. A cabeça bem-feita: repensar a reforma, reformar o pensamento. 24 ed. Rio de Janeiro: Bertrand Brasil, 2018.

MORIN, E. Introdução ao pensamento complexo. Tradução Eliane Barbosa. 5.ed. Porto Alegre: Sulina, 2015.

NICOLESCU, B. O manifesto da transdisciplinaridade. São Paulo: TRIOM, 1999.

PERNAMBUCO, M.M.C.A.; SILVA, A.F.G. Paulo Freire: uma proposta pedagógica ético-crítica para a Educação Ambiental. In: Educação Ambiental: dialogando com Paulo Freire. LOUREIRO, C. F. B.; TORRES, J. R. (Orgs.). São Paulo: Cortez, 2014.

REIGOTA, M. O que é Educação Ambiental. 2. ed. São Paulo: Brasiliense, 2014. 